\title{
Novel Formation of Ectopic (Nonplacental) Capsaicinoid Secreting Vesicles on Fruit Walls Explains the Morphological Mechanism for Super-hot Chile Peppers
}

\author{
Paul W. Bosland ${ }^{1,4}$ and Danise Coon ${ }^{2}$ \\ Chile Pepper Institute, New Mexico State University, P.O. Box 30003, MSC 3Q, Las Cruces, \\ NM 88003 \\ Peter H. Cooke ${ }^{3}$ \\ Core University Research Resources Laboratory, New Mexico State University, Las Cruces, \\ NM 88003
}

\begin{abstract}
AdDitional IndeX words. bell pepper, Capsicum, jalapeno, pericarp, placental tissue, pungency, stereofloursence
Abstract. Chile peppers (Capsicum sp.) are one of the most important spices in the world and a significant vegetable, providing substantial amounts of vitamins $A$ and $C$. Chile peppers are also used as a medicinal and lachrymator plant because of the characteristic burning sensation they cause when consumed by mammals. This sensation is caused by capsaicinoids that are alkaloids produced in vesicles inside the fruit. A novel class of chile peppers known as "super-hots" having greater than 1 million Scoville heat units have generated much interest. We compared the morphological structure of fruit pericarp and placental tissue of "super-hot" chile peppers to those of jalapeno and bell pepper. Most chile peppers including jalapenos, only produce the capsaicinoids in secreting vesicles found on the placenta. We report on the novel discovery that these "super-hot" chile peppers have developed accessorial vesicles on the pericarp tissue in addition to the vesicles on the placental tissue, thus leading to exceedingly high Scoville heat units for these plants.
\end{abstract}

Chile peppers are one of the first crops domesticated in the Western Hemisphere about 10,000 BCE (Perry et al., 2007). In fact, the Capsicum genus was so important to humans that when they came into contact with it, five different Capsicum species in separate regions of the Americas were independently domesticated. One possible reason for such an early domestication is that chile peppers are well known as medicinal plants by indigenous peoples (Cichewicz and Thorpe, 1996).

The capsaicinoids, only found in the Capsicum genus, have the ability to elicit the sensation of a burning pain in mammals. The capsaicinoids are the most probable reason for the early adoption as a medicinal plant. The capsaicinoids have been traditionally used to relieve pain. The mechanism of action of capsaicinoids in mammals has been extensively studied over the past decade (Caterina et al., 2000). The capsaicin (vanilloid) transient cation channel subfamily $\mathrm{V}$ member 1 (TrpV1) receptor is a cation channel expressed by primary sensory neurons of the "pain" pathway. It has been established that the capsaicinoids bind to the TrpV1 receptor signaling "heat" to the brain (Huang et al., 2013).

The heat level of a chile pepper can be determined using chemical, instrumental, or sensorial methods (Wall and Bosland, 1998). The Scoville organoleptic heat test is a subjective measure of chile pepper heat using human tasters (Scoville,

Received for publication 18 Feb. 2015. Accepted for publication 13 Mar. 2015. A contribution of the New Mexico Agr. Expt. Sta., New Mexico State University, Las Cruces, NM.

${ }^{1}$ Regents Professor.

${ }^{2}$ Senior Research Specialist.

${ }^{3}$ Director, Electron Microscopy Lab.

${ }^{4}$ Corresponding author. E-mail: pbosland@nmsu.edu.
1912). Today, the most reliable, rapid, and efficient method to identify and quantify capsaicinoids is high-performance liquid chromatography (HPLC); the results of which can be converted to Scoville heat units by multiplying the parts per million by 16 (Collins et al., 1995; Yao et al., 1994).

In 2006, Bosland and Baral (2007) reported that "Bhut Jolokia," a natural interspecific hybrid between Capsicum chinense and Capsicum frutescens grown in India, surpassed 1 million Scoville heat units. Later in 2012, the 'Scorpion' chile pepper from Trinidad had a heat level greater than 2 million Scoville heat units (Bosland et al., 2012). Chile peppers with a heat level greater than 1 million Scoville heat units are now known in the vernacular as "super-hots."

In Capsicum the heat level is both a qualitative and a quantitative trait. The ability for the fruit to be hot or not can be inherited as a single dominant gene, Punl (Pungency) located on chromosome 2. A second gene for lack of heat in the fruit is described in $C$. chinense and is caused by the absence of vesicles on the placental tissue, Loss of Vesicles [Lov (Bosland and Votava, 2012)]. The quantitative aspect of heat level is based on the concentration of capsaicinoids that accumulate in the vesicles on the placental walls (Suzuki et al., 1980). The recent sequencing of the Capsicum genome strongly suggests that capsaicinoid production originated through the evolution of new genes by unequal duplication of existing genes and owing to changes in gene expression in fruit after speciation (Kim et al., 2014). Wide variation in capsaicinoid content has been introduced through domestication into cultivated species of chile peppers.

Our current understanding is that capsaicinoids are only synthesized in the epidermal cells on the interlocular septum 
(placenta) and are stored in elevated vesicles only on the surface of the placental tissue in a Capsicum fruit (AnconaEscalante et al., 2013; Fujiwake et al., 1980; Keyhaninejad et al., 2014). The interlocular septum defines the fruit locules and is derived from the tissue connecting the placenta to the pericarp (Esau, 1977; Iwai et al., 1979; Judd et al., 1999). The epidermal cells of the interlocular septum have been implicated in capsaicinoid biosynthesis based on morphological changes during fruit development and the existence of osmiophilic granules in these cells (Furuya and Hashimoto, 1954; Ohta and Chuong, 1975; Suzuki and Iwai, 1984). When the cellular structure of the placenta was examined using a light microscope (Fujiwake et al., 1980), it was noted that distinctive morphological changes occurred in the placenta during the maturation. Epidermal protrusions or blisters arise from the lifting and splitting of the cuticle layer from the cell wall during the filling of subcuticular cavities with the oleoresin capsaicinoid (Rao and Paran, 2003; Rowland et al., 1983; Zamski et al., 1987). Heat associated with seeds is due to the small amounts of capsaicinoids detected on the seeds due owing to surface contamination during dissection (Huffman et al., 1978).

We report on the widespread distribution of vesicles on the entire pericarp to explain the exceedingly high Scoville heat units of the "super-hot" chile peppers.

\section{Materials and Methods}

Fruit of the cultivars Trinidad Moruga Scorpion, Trinidad Scorpion, Bhut Jolokia, Early Jalapeno, and Keystone bell pepper were all harvested at the horticulturally mature fruit stage and carefully dissected along the locular septa, exposing the locules. The pericarps lining the locules were carefully removed so the placental tissue would not be disturbed. The pericarp and placental tissues were then oven-dried separately from one another at $42{ }^{\circ} \mathrm{C}$ until tissues were completely dry. After drying, the samples were ground according to the American Spice Trade Association method (ASTA, 1997). The capsaicinoid content in placenta and pericarp tissue of each selected fruit was evaluated. Capsaicinoids were quantified with HPLC according to the method reported by Collins et al. (1995).

For the microscopic observations, three fruit pods of each cultivar were harvested. The distribution of oleoresin in capsaicinoid-containing vesicles on the pericarps and placentas was examined both with reflected white light from a ring lamp and by epifluorescence optics using a stereofluorescence microscope (model M165FC; Leica Microsystems, Buffalo Grove, IL), equipped with an external light source (model EL6000), for viewing fluorescence and a color charge-coupled device (CCD) camera (model DFC 310) for collecting digital images through the integrated application software. Vesicles associated with the placentas and septa of locules in pungent cultivars of chile peppers can be identified through the fluorescent properties of the capsaicinoids (Rao and Paran, 2003; Rowland et al., 1983; Zamski et al., 1987). Typically, the oleoresin containing capsaicinoids fluoresces blue or green-yellow in the range of 530$600 \mathrm{~nm}$ when excited with violet or blue light or when measured in the emission spectrum mode using a confocal microscope (Cooke, personal observation). A green fluorescent protein 1 (gfp1) filter set was used to examine the tissues for oleoresin capsaicinoid fluorescence. When viewed with a gfp1 filter set, the vesicles on placentas and locular septa were uniquely fluorescent, except for a uniform and bright autofluorescence from the surfaces of the seeds. Hence we used the gfp1 filter set (ex $=425 \mathrm{~nm}$, pass $>480 \mathrm{~nm}$ ) to visualize and measure the extent and distribution of capsaicinoid containing vesicles selectively and estimate the amounts of vesicular areas in the dissected fruit pods. Digital color images were converted and calibrated into gray level images, "surface flattened," and threshold segmented by eye to match fluorescent areas using Fovea Pro 4 plug-ins (Reindeer Graphics, Asheville, NC) in a PhotoShop CS4 Extended graphics software program (Adobe Systems, San Jose, CA).

\section{Results}

Each of the "super-hot" cultivars tested had significant amounts of capsaicinoids in the pericarp samples as well as in the placenta samples from the dissected fruit pods, resulting in a Scoville heat unit rating for pericarp and placenta separately (Table 1). 'Early Jalapeno', a hot Capsicum annuum jalapenotype chile pepper, had 0 Scoville heat units rating for the pericarp analysis, whereas the placental tissue had a positive Scoville heat units rating. The bell pepper, 'Keystone', with the genetic allele, pun-1, which is unable to produce the capsaicinoids, and known for not having any heat, had zero Scoville heat units ratings for both the pericarp and placenta.

Each of the "super-hot" cultivars observed with a stereofluorescence microscope showed individual vesicles containing capsaicinoids throughout the pericarp and placental tissues. With the gfp1 filter set, the vesicles were uniquely fluorescent (Figs. 1 and 2). The "super-hot" cultivars all had very large

Table 1. The Scoville heat units (SHU) for each Capsicum cultivar tested individually for pericarp and placenta tissues.

\begin{tabular}{lrr}
\hline Cultivar & $\begin{array}{c}\text { Pericarp heat } \\
\text { level (SHU) }\end{array}$ & $\begin{array}{c}\text { Placenta } \\
\text { heat level (SHU) }\end{array}$ \\
\hline Trinidad Moruga & $1,487,088$ & $1,131,035$ \\
$\quad$ Scorpion & & $1,278,392$ \\
Trinidad Scorpion & $1,233,250$ & $1,332,789$ \\
Bhut Jolokia & 311,207 & 16,155 \\
Early Jalapeno & 0 & 0 \\
Keystone bell pepper & 0 & \\
\hline
\end{tabular}

A.

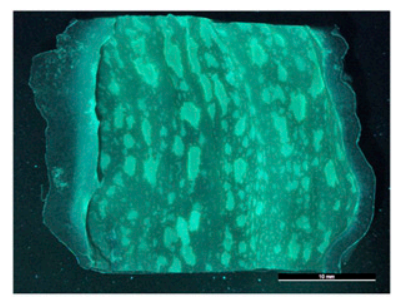

B.

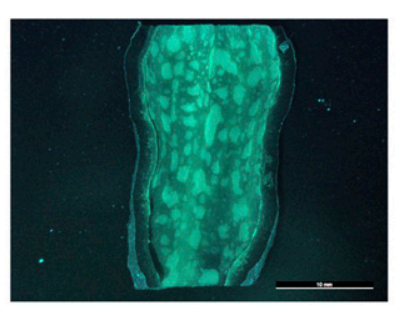

C.

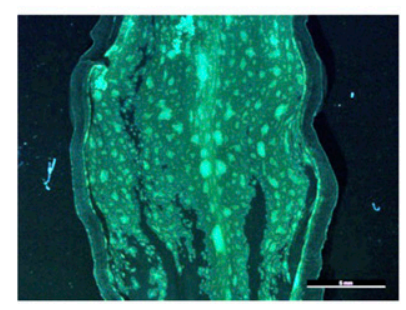

Fig. 1. Capsaicinoid vesicles in the pericarpal tissue of the superhot chile pepper cultivars: (A) Trinidad Moruga Scorpion, (B) Trinidad Scorpion, and (C) Bhut Jolokia taken with a stereo-fluorescence microscope. 
A.

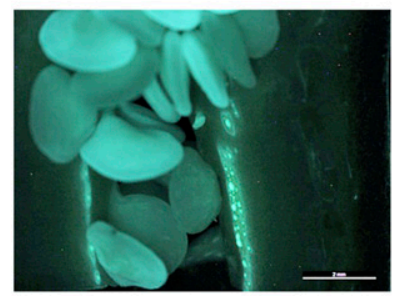

B.

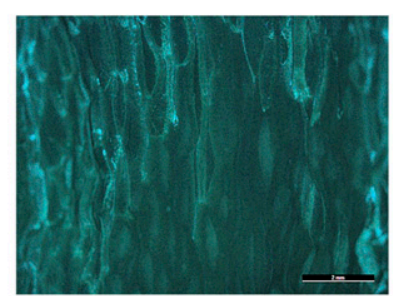

Fig. 2. Stereo-fluorescence microscopy of the chile pepper cultivars: (A) Early Jalapeno pericarp showing no capsaicinoid vesicles, (B) Early Jalapeno placenta showing vesicles containing capsaicinoids, and (C) Keystone bell pepper pericarp showing no vesicles.

percentages of the pericarp covered with vesicles (i.e., 'Moruga Scorpion' $\geq 60 \%$, 'Trinidad Scorpion' $\geq 54 \%$, 'Bhut Jolokia' $\geq 43 \%$ in projected areas of about $200-500 \mathrm{~mm}^{2}$ of pericarps), whereas the pericarps of 'Early Jalapeno' and 'Keystone' bell pepper had no detectable fluorescence, indicating no capsaicinoids were formed. In addition, 'Orange Habanero' fruit walls were examined, and no vesicles were seen (P. Cooke, personal observation).

\section{Discussion}

The heat, or burning sensation is an important and distinguishing chile pepper quality trait, and the most unique for chile peppers. Understanding how to regulate and increase the Scoville heat unit levels in chile peppers is of interest to food and industrial processing industries. In this study, it was determined by HPLC and auto-fluorescence, that the three "super-hot" cultivars, Trinidad Moruga Scorpion, Trinidad Scorpion, and Bhut Jolokia have very high levels of heat because all produce vesicles containing capsaicinoids on the entire pericarpal tissues in the fruit. This is the first report demonstrating that capsaicinoid producing vesicles are expressed on the pericarp tissue. "Super-hot" chile peppers are created by a novel phenotype and genotype that allows for capsaicinoid secreting vesicles to form on the pericarp tissue. These results will be important to plant breeders, food processors, and the capsaicinoid extraction industry.

\section{Literature Cited}

Ancona-Escalante, W. del R., F.M. Baas-Espinola, L.A. CastroConcha, F.A. Vázquez-Flota, M. Zamudio-Maya, and M.L. de Miranda-Ham. 2013. Induction of capsaicinoid accumulation in placental tissues of Capsicum chinense Jacq. requires primary ammonia assimilation. Plant Cell Tissue Organ Cult. 113:565-570. American Spice Trade Association. 1997. Official analytical methods of the American Spice Trade Association. Amer. Spice Trade Assn., Englewood Cliffs, NJ.

Bosland, P.W. and J.B. Baral. 2007. 'Bhut Jolokia'-The world's hottest known chile pepper is a putative naturally occurring interspecific hybrid. HortScience 42:222-224.

Bosland, P.W., D. Coon, and G. Reeves. 2012. 'Trinidad Moruga Scorpion' pepper is the world's hottest measured chile pepper at more than 2 million Scoville heat units. HortTechnology 22:534-538.

Bosland, P.W. and E.J. Votava. 2012. Peppers: Vegetable and spice capsicums. CAB Intl., Wallingford, UK.

Caterina, M.J., A. Leffer, A.B. Malmberg, W.J. Martin, J. Trafton, K.R. Petersen-Zeitz, M. Koltzenburg, A.I. Basbaum, and D. Julius. 2000. Impaired nociception and pain sensation in mice lacking the capsaicin receptor. Science 288:306-313.
C.

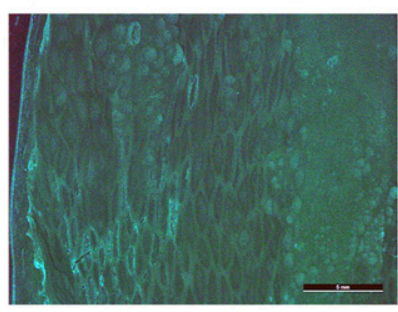

Cichewicz, R.H. and P.A. Thorpe. 1996. The antimicrobial properties of chile peppers (Capsicum species) and their uses in Mayan medicine. J. Ethnopharmacol. 52:61-70.

Collins, M.D., L. Mayer-Wasmund, and P.W. Bosland. 1995. Improved method for quantifying capsaicinoids in Capsicum using high-performance liquid chromatography. HortScience 30:137-139.

Esau, K. 1977. Anatomy of seed plants. Wiley, New York, NY.

Fujiwake, H., T. Suzuki, and K. Iwai. 1980. Intracellular localization of capsaicin and its analogues in Capsicum fruit. The vacuole as the intracellular accumulation site of capsaicinoid in the protoplast of Capsicum fruit. Plant Cell Physiol. 21:10231030.

Furuya, T. and K. Hashimoto. 1954. Studies on Japanese Capsicum. Distribution of capsaicin-secreting organs in Capsicum plant. J. Pharmaceutical Soc. Jpn. 74:771-772.

Iwai, K., T. Susuki, and H. Fujiwaki. 1979. Simultaneous microdetermination method of capsaicin and its four analogues by HPLC and GC/MS. J. Agr. Food Chem. 172:303-311.

Huang, F., J.Y. Xue, A.Q. Jiang, and H.-L. Zhu. 2013. Capsaicin and its analogues: Structure-activity relationship study. Curr. Med. Chem. 20:2661-2672.

Huffman, V.L., E.R. Schadle, B. Villalon, and E.E. Burns. 1978. Volatile components and pungency in fresh and processed jalapeno peppers. J. Food Sci. 43:1809-1811.

Judd, W.S., C.S. Campbell, E.A. Kellogg, and P.F. Stevens. 1999. Plant systematics: A phylogenetic approach. Sianuer Assoc., Sunderland, MA.

Keyhaninejad, N., J. Curry, J. Romero, and M.A. O'Connell. 2014. Fruit specific variability in capsaicinoid accumulation and transcription of structural and regulatory genes in Capsicum fruit. Plant Sci. 215/216:59-68.

Kim, S., M. Park, S.I. Yeom, Y.M. Kim, J.M. Lee, H.A. Lee, E. Seo, J. Choi, K. Cheong, K.T. Kim, K. Jung, G.W. Lee, S.K. Oh, C. Bae, S.B. Kim, H.Y. Lee, S.Y. Kim, M.S. Kim, B.C. Kang, Y.D. Jo, H.B. Yang, H.J. Jeong, W.H. Kang, J.K. Kwon, C. Shin, J.Y. Lim, J.H. Park, J.H. Huh, J.S. Kim, B.D. Kim, O. Cohen, I. Paran, M.C. Suh, S.B. Lee, Y.K. Kim, Y. Shin, S.J. Noh, J. Park, Y.S. Seo, S.Y. Kwon, H.A. Kim, J.M. Park, H.J. Kim, S.B. Choi, P.W. Bosland, G. Reeves, S.H. Jo, B.W. Lee, H.T. Cho, H.-S. Choi, M.S. Lee, Y. Yu, Y.D. Choi, B.S. Park, A. van Deynze, H. Ashrafi, T. Hill, W.T. Kim, H.S. Pai, H.K. Ahn, I. Yeam, J.J. Giovannoni, J.K.C. Rose, I. Sørensen, S.J. Lee, R.W. Kim, I.Y. Choi, B.S. Choi, J.S. Lim, Y.H. Lee, and D. Choi. 2014. Genome sequence of the hot pepper provides insights into the evolution of pungency in Capsicum species. Nat. Genet. 46:270-278.

Ohta, Y. and P.V. Chuong. 1975. Hereditary changes in Capsicum annuum. L.I. induced by ordinary grafting. Euphytica 24:335-368.

Perry, L., R. Dickau, S. Zarrillo, I. Holst, D.M. Pearsall, D.R. Piperno, M.J. Berman, R.G. Cooke, K. Rademaker, A.J. Ranere, J.S. Raymond, D.H. Sandweiss, F. Scaramelli, K. Tarble, and J.A. Zeidler. 2007. Starch fossils and the domestication and dispersal of chili peppers (Capsicum spp. L.) in the Americas. Science 315:986-988.

Rao, G.U. and I. Paran. 2003. Polygalacturonase: A candidate gene for the soft flesh and deciduous fruit mutation in Capsicum. Plant Mol. Biol. 51:135-141.

Rowland, B.J., B. Villalon, and E.E. Burns. 1983. Capsaicin production in sweet bell and pungent jalapeno peppers. J. Agr. Food Chem. 312:484-487.

Scoville, W.L. 1912. Note on Capsicum. J. Amer. Pharmacol. Assn. 1:453.

Suzuki, T., H. Fujiwake, and K. Iwai. 1980. Intracellular localization of capsaicin and its analogues in Capsicum fruit. I. Microscopic 
investigation of the structure of the placenta of Capsicum annuum var. annuum cv. Karayatsubusa. Plant Cell Physiol. 21:839-853.

Suzuki, T. and K.Y. Iwai. 1984. Constituents of red pepper spices: Chemistry, biochemistry, pharmacology and food science of the pungent principles of Capsicum species, p. 227-299. In: A. Brossi (ed.). The alkaloids: Chemistry and pharmacology. Vol. XXIII. Academic Press, New York, NY.

Wall, M.M. and P.W. Bosland. 1998. Analytical methods for color and pungency of chiles (Capsicum), p. 347-373. In: G. Charalambous (ed.). Instrumental methods in food and beverage analysis. Elsevier Science Publishers, Amsterdam, The Netherlands.

Yao, J.P., M.G. Nair, and A. Chandra. 1994. Supercritical carbondioxide extraction of Scotch Bonnet (Capsicum annuum) and quantification of capsaicin and di-hydrocapsaicin. J. Agr. Food Chem. 42:1303-1305.

Zamski, E., O. Shoham, D. Palevitch, and A. Levy. 1987. Ultrastructure of capsaicinoids-secreting cells in pungent and non-pungent red pepper (Capsicum annuum L.) cultivars. Bot. Gaz. 148:1-6. 